Research Article

\title{
Selected Morbidities among Workers of an Adhesive Plaster Industry in Goa
}

\author{
Mahika V Naik', Kalyani S', Jagadish A Cacodcar ${ }^{3}, \underline{V i s h w a r a j ~ K M h a l s h e k a r ~}^{4}$, \\ Sweta V Mhalshekar \\ ${ }^{1,2}$ PG Student, ${ }^{3}$ Professor and Head, Department of Preventive and Social Medicine, Goa Medical College, Bambolim, Goa. \\ ${ }^{4}$ Manager (Medical and OHSE), Goa Shipyard Limited, Vasco da Gama, Goa. \\ ${ }^{5}$ Managing Director, Siddhivinayak, Occupational Health Services. \\ DOI: https://doi.org/10.24321/2454.325X.202007
}

I $\quad \begin{array}{lllll}\mathbf{N} & \mathbf{F} & \mathbf{O}\end{array}$

\section{Corresponding Author:}

Kalyani S, Department of Preventive and Social Medicine, Goa Medical College, Bambolim, Goa.

E-mail Id:

kalloose1705@gmail.com

Orcid Id:

https://orcid.org/0000-0003-4170-3784

How to cite this article:

Naik MV, Kalyani S, Cacodcar JA, Mhalshekar VK, Mhalshekar SV. Selected Morbidities among Workers of an Adhesive Plaster Industry in Goa. Int J Preven Curat Comm Med 2020; 6(2): 12-15.

Date of Submission: 2020-07-03

Date of Acceptance: 2020-09-20

\section{$\begin{array}{llllllllll}\mathbf{A} & \mathbf{B} & \mathbf{S} & \mathbf{T} & \mathbf{R} & \mathbf{A} & \mathbf{C} & \mathbf{T}\end{array}$}

Background: The toxic nature of chemicals \& pollutants associated with an adhesive plaster industry is well established. A disastrous health sequel would occur among workers of these industries due to exposure to pollution, created \& stored wastes, and constant noise \& bright light.

Objective: To describe selected morbidities among workers in an adhesive plaster industry in Goa.

Methodology: The study was conducted over a period of two months during which, the data of 135 workers was obtained from an Occupational Health and Safety (OHS) Centre catering to an adhesive plaster industry in North Goa which conducted periodic medical check-ups of these workers. The data included socio-demographic characteristics and details regarding selected morbidities among the workers of the adhesive plaster industry.

Result: Among 135 workers, the mean age was $40.96 \pm 11.1$ years. Majority of the participants were males. It was observed that $5(3.7 \%)$ had a known history of diabetes and 48 (35.6\%) were hypertensive. Near-vision abnormalities were seen among 66 (48.9\%), whereas 60 (44.4\%) had uncorrected far-vision abnormalities. Obesity was detected among 6 (4.4\%) whereas 40 (29.6\%) were overweight. Obstructive \& restrictive respiratory diseases were seen in 3 (2.2\%) \& 40 (29.6\%) persons respectively. Audiometry reports revealed 4 (3\%) workers had mild to moderate hearing loss.

Conclusion: Workers in the adhesive plaster industry suffered from several lifestyle diseases like diabetes, hypertension, obesity, as well as occupational diseases like audio-visual impairment and lung diseases. This study emphasizes the importance of periodic medical examinations for timely detection \& appropriate treatment of the health conditions among such workers.

Keywords: Morbidities, Workers, Adhesive Plaster Industry 


\section{Introduction}

Occupational health has been defined by the World Health Organization (WHO) in association with the International Labor Organization (ILO) as 'the promotion and maintenance of the highest degree of physical, mental and social wellbeing of workers in all occupations by preventing departures from health, controlling risks and the adaptation of work to people, and people to their jobs. ${ }^{1}$ Although the focus of occupational health has been on work-related injuries and hazards, there is an increased recognition for the need of a holistic approach to ensure the health of working men and women. The Global Plan of Action devised by the WHO emphasizes on social and individual factors, and access to health services. ${ }^{2}$ National Institute for Occupational Safety and Health (NIOSH), a wing of the Centres for Disease Control and Prevention (CDC), Atlanta recently rolled out a Total Worker Health Program, which is an integrated approach of risk factors intended to protect workers from work-related injury and to help them advance their overall health and wellbeing, on and off the job. The approach includes addressing exposures at work, environmental factors and personal factors. ${ }^{3}$

In India, labour is a subject in the concurrent list where both the Central and the State Governments are competent to enact legislation subject to certain matters reserved for the Central Government. ${ }^{4}$ There are multiple laws and legislation dealing with the health of workers which are enacted to varying degrees by states. The Occupational Health and Safety Centre (OHS) in Goa was established within this framework. The Goa Factories Rules outlines the various actions taken in terms of protection and audit of the health of industrial workers. ${ }^{5}$

Adhesive plaster industry is the manufacture and supply of medical and non-medical adhesive tapes. The industrial process involves exposure to plastics, hot fumes, and synthetic resins. ${ }^{6}$ Chronic exposure to thermal decomposition products of polymers has been long established to be associated with the possibility of sensory irritation and physiological stress. ${ }^{7}$ Upper and lower respiratory tract inflammation has been documented in similar industries that work with heated resins. ${ }^{8}$ All mechanized environments without appropriate sound proofing has the potential for hearing impairment. Chemical exposure is shown to cause additional hearing impairment in workers. ${ }^{9}$ In addition to these, co-morbidities like lifestyle diseases can also be result due to work stress and work hours.

The health profile of workers of the adhesive plaster industry has not been published so far in India. Understanding and documenting the morbidity status is important to guide policy makers. Therefore, this study was done to assess the morbidity status of persons employed at adhesive plaster factories in Goa.

\section{Materials and Methods}

It was a record based cross-sectional descriptive study conducted over a period of two months during November and December 2019. An Occupational Health and Safety (OHS) center caters to all major industries in North Goa where periodic medical check-ups are routinely conducted and recorded. The details required for the study were collected from the records maintained at the center. The study population was all workers employed in the adhesive plaster industry in Goa. Inclusion criteria was to have their complete details registered at the OHS center and at least one complete check-up having been done in the previous year. All records with incomplete or ambiguous data were excluded. The data collected included socio-demographic details and specificities regarding selected morbidities like diabetes, hypertension, heart disease, visual impairment, hearing impairment and lung disease identified through the medical check-up. There was no contact between investigators and the study participants. No tests were additionally performed as part of the study.

As there were no previous studies pertaining to this industry, minimum sample size was calculated by assuming the proportion of lung disease to be $50 \%$ with $10 \%$ absolute precision and $95 \%$ confidence interval, to be 96 . But all eligible records available were included into the study, and no sampling was employed.

Data was entered in Microsoft Excel sheet and analyzed using Statistical Package for Social Sciences version 22 and Open Epi. ${ }^{10-12}$ Age was expressed as mean (SD) and other variables as simple percentages \& proportions along with $95 \%$ confidence interval. Ethical approval was taken from the Institutional Ethics Committee (IEC) of Goa Medical College before the commencement of the study. Confidentiality was assured to the Occupational health physician in charge with respect to the names of the adhesive plaster factory and identity of the employees. Consent was waived off as it was record-based.

\section{Result}

The socio-demographic details of study participants are given in Table 1. Out of the 135 workers, 115 (85.9\%) were males \& 19 (14.1\%) were females. Majority of the workers (33.3\%) belonged to the age group of 50 to 59 years.

Tables 2, 3 and 4, show the various morbidities identified in the workers. Sugar profile of the workers revealed that $3.7 \%$ had diabetes and $35.6 \%$ were hypertensive. Visual acuity testing proved that 60 (44.4\%) had hypermetropia, and $66(48.9 \%)$ had corrected myopic vision with spectacles. One of the workers was diagnosed with color blindness. Spirometry findings revealed that 40 workers $(29.6 \%)$ suffered from chronic restrictive lung disease and $3(2.2 \%)$ had obstructive lung disease. Four workers (3\%) had mild 
to moderate hearing loss. ECG finding were normal in over $97 \%$. Over $29.6 \%$ were in overweight range of body mass index, 6 (4.4.\%) were obese and five (4.02\%) were underweight.

Table I.Socio-demographic details of persons working at an adhesive plaster factory in North Goa $(\mathbf{N}=135)$

\begin{tabular}{|c|c|c|}
\hline Variable & Frequency & Percentage \\
\hline Age (in years) & & \\
\hline $20-29$ & 25 & 18.5 \\
\hline $30-39$ & 43 & 31.8 \\
\hline $40-49$ & 21 & 15.6 \\
\hline $50-59$ & 46 & 34.1 \\
\hline Gender & & \\
\hline Male & 116 & 85.9 \\
\hline Female & 19 & 14.1 \\
\hline
\end{tabular}

Table 2.Distribution of study participants by presence of cardiovascular risk factors $(\mathbf{N}=135)$

\begin{tabular}{|c|c|c|}
\hline Variable & $\begin{array}{c}\text { Frequency } \\
(\%)\end{array}$ & $\begin{array}{c}\mathbf{9 5 \%} \text { Confidence } \\
\text { Interval }\end{array}$ \\
\hline Diabetes mellitus & $5(3.7)$ & $1.6-8.4$ \\
\hline Present & $130(96.3)$ & $91.6-98.4$ \\
\hline Absent & & \\
\hline Hypertension & $48(35.6)$ & $28.0-43.9$ \\
\hline Present & $87(64.4)$ & $56.1-72.0$ \\
\hline Absent & & \\
\hline Heart Disease & $4(3.0)$ & $1.2-7.4$ \\
\hline Present & $131(97.0)$ & $92.6-98.8$ \\
\hline Absent & & \\
\hline Body Mass Index & $6(4.4)$ & $2.1-9.4$ \\
\hline Underweight & $83(61.5)$ & $53.1-69.3$ \\
\hline Normal & $40(29.6)$ & $22.6-37.8$ \\
\hline Overweight & $6(4.4)$ & $2.1-9.4$ \\
\hline Obese & & \\
\hline
\end{tabular}

Table 3.Distribution of study participants by visual and auditory morbidities $(\mathbf{N}=135)$

\begin{tabular}{|c|c|c|}
\hline Variable & Frequency (\%) & $\begin{array}{c}\text { 95\% Confidence } \\
\text { Interval }\end{array}$ \\
\hline Near Vision & & \\
\hline Normal & $69(51.1)$ & $42.8-59.4$ \\
\hline Abnormal & $66(48.9)$ & $40.6-57.2$ \\
\hline Far Vision & & \\
\hline Normal & $75(55.6)$ & $47.1-63.7$ \\
\hline Abnormal & $60(44.4)$ & $36.3-52.9$ \\
\hline
\end{tabular}

\begin{tabular}{|c|c|c|}
\hline Color Vision & & \\
\hline Normal & $134(99.3)$ & $95.9-99.9$ \\
\hline Abnormal & $1(0.7)$ & $0.1-4.1$ \\
\hline Hearing & & \\
\hline Normal & $131(97.0)$ & $92.6-98.8$ \\
\hline Abnormal & $4(3.0)$ & $1.2-7.4$ \\
\hline
\end{tabular}

Table 4.Distribution of study participants by presence of respiratory disease $(\mathrm{N}=135)$

\begin{tabular}{|c|c|c|}
\hline Variable & $\begin{array}{c}\text { Frequency } \\
\text { (\%) }\end{array}$ & $\begin{array}{c}95 \% \\
\text { Confidence } \\
\text { Interval }\end{array}$ \\
\hline Respiratory Disease & & \\
\hline Restrictive Lung Disease & $39(28.9)$ & $21.9-37.0$ \\
\hline Obstructive Lung Disease & $3(2.2)$ & $0.8-6.3$ \\
\hline Mixed Disease & $2(1.5)$ & $0.4-5.2$ \\
\hline No disease & $91(67.4)$ & $59.1-74.7$ \\
\hline
\end{tabular}

\section{Discussion}

In the present study among 135 workers, spirometry tests revealed that nearly one-third workers suffered from chronic restrictive lung disease and $2.2 \%$ had obstructive lung disease. A study conducted by Saiyed $\mathrm{HN}$ et al reported the prevalence of obstructive lung disease to be $9 \%$ in asbestos textile workers; $48.8 \%$ in jute mill workers; $30 \%$ in other textile workers. ${ }^{13}$ This difference in finding may be due to the fact that workers in adhesive plaster industry are less exposed to gaseous form of the chemicals released during the manufacturing process compared to the textile industry workers. In our study, it was observed that the prevalence of diabetes among workers was 3.7\%. A study done by Henneberger et al in paper \& pulp mill workers it was reported that there is no significantly high mortality due to diabetes mellitus among these workers compared to general population. ${ }^{14}$ Similar findings were reported by Suri et al in their study among workers among manufacturing sector of India. ${ }^{15}$ The workers in such chemical processing industries may have shift works leading to irregular food intake and may usually be exposed to heat stress during mechanical operations which might be the reason behind the development of diabetes mellitus as pointed out by Black et al. ${ }^{16}$ Chemical agents may cause hearing loss when acting alone or in interaction with the noise. Audiometry findings in our study revealed that $3 \%$ of the workers had mild to moderate hearing loss. High frequency hearing losses were reported in workers exposed to aromatic solvents and noise at an oil refinery. In our study it was found that $35.6 \%$ were hypertensive which was similar to the findings of Hoe et al which reported that workers who were chronically exposed to high level styrene in plastic 
product manufacturing factories were hypertensive. Also, Goncalves et al explained that workers exposed to $\mathrm{SO}_{2}, \mathrm{CO}_{2}$ showed hypertensive changes. ${ }^{17}$

\section{Conclusion}

Hypertension and increased BMI are the most common lifestyle related morbidities in persons working in adhesive plaster industry. Nearly half suffer from visual abnormalities and nearly third from restrictive lung disease. Periodic check-ups are necessary to ensure that the workers get adequate and timely diagnosis and management.

\section{Conflict of Interest: None}

\section{References}

1. What is Occupational Health? [Internet]. [cited 2020 Jun 30]. Available from: http://www.agius.com/hew/ resource/ohsilo.htm.

2. WHO | About occupational health [Internet]. WHO. World Health Organization; [cited 2020 Jun 30]. Available from: https://www.who.int/occupational_ health/about/en/.

3. Using Total Worker Health ${ }^{\circledR}$ Concepts to Address Hearing Health (2019-155). 2019 Sep 27 [cited 2020 Jun 30]; Available from: https://www.cdc.gov/niosh/ docs/wp-solutions/2019-155/default.html.

4. India. National Occupational Safety and Health Profile. New Delhi: Directorate General Factory Advice Service and Labor Institutes; 2013.

5. India. The Goa Factories (Occupational Safety and Health Audit) Rules 2014. Goa: Government Gazette Notification; 2014. Available from https://ifbgoa.goa. gov.in/sites/default/files/The_Goa_Occ_Safety Health_Audit_Rules_2014_updated_upto_1st_ Amendment.pdf.

6. Lauk W. Pharmaceutical adhesive plaster and method for manufacturing it [Internet]. US4695277A, 1987 [cited 2020 Jun 30]. Available from: https://patents. google.com/patent/US4695277A/en.

7. Alarie YC, Anderson RC. Toxicologic and acute lethal hazard evaluation of thermal decomposition products of synthetic and natural polymers. Toxicol Appl Pharmacol 1979; 51(2): 341-362.

8. doPICO GuA, Rankin J, Chosy LW, Reddan WG, Barbee R, Gee B, et al. Respiratory Tract Disease from Thermosetting Resins. Ann Intern Med 1975; 83(2): 177-184.

9. Campo P, Morata TC, Hong O. Chemical exposure and hearing loss. Dis--Mon DM 2013; 59(4): 119-138.

10. Microsoft Excel, Spreadsheet Software, Excel Free Trial [Internet]. [cited 2020 Jun 8]. Available from: https:// www.microsoft.com/en-us/microsoft-365/excel.

11. SPSS Software [Internet]. 2020 [cited 2020 Jun 14]. Available from: https://www.ibm.com/analytics/spss- statistics-software.

12. OpenEpi Menu [Internet]. [cited 2019 Jul 27]. Available from: http://www.openepi.com/Menu/OE_Menu.htm

13. Saiyed $\mathrm{HN}$ et al. Occupational health research in smallscale industries in India. Ind Health 2004: 42(2): 141-148

14. Henneberger et al. Changes of physiological levels of risk factors contributing to induction of metabolic syndrome in workers chronically exposed to styrene. J Korean Soc Occup Environ Hyg (2009); 19: 30-38.

15. Suri $S$ et al. Occupational health profile of workers employed in manufacturing sector of India. Natl Med J India 2016; 29(5): 277-281.

16. Black $M$ et al. The health risks of informal waste workers in the Kathmandu Valley: a cross-sectional survey. Public Health 2019; 166: 10-18. DOI: 10.1016/j. puhe.2018.09.026. Epub 2018 Nov 9.

17. Goncalves F et al. Influences of the weather and air pollutants on cardiovascular diseases in metropolitan area workers. Environ Res 2007; 104: 275-281. DOI: 10.1016/j.envres.2007.01.004. 